\title{
Abrupt glacier motion and reorganization of basal shear stress following the establishment of a connected drainage system
}

\author{
Jeffrey L. Kavanaugh, "Garry K. C. Clarke \\ Department of Earth and Ocean Sciences, University of British Columbia, Vancouver, British Columbia V6T 124, Canada
}

\begin{abstract}
Three episodes of strong basal motion occurred at Trapridge Glacier, Yukon Territory, Canada, on 11 June 1995 following the establishment of a connected subglacial drainage system. Responses to these "spring events" are noted in the records for 42 instruments and were recorded throughout the $\sim 60000 \mathrm{~m}^{2}$ study area. Strong basal motion during the events is indicated by ploughmeter, load-bolt and vertical-strain records, and abrupt pressure changes in several transducer records denote damage caused by extreme pressure pulses. These pressure pulses, generated by the abrupt basal motion, also resulted in the failure of seven pressure sensors. Records for pressure, turbidity and conductivity sensors indicate that basal drainage patterns did not change significantly during the events. Geophone records suggest that the episodes of basal motion were precipitated by the gradual failure of a "sticky spot" following hydraulic connection of part of the study area. This failure resulted in the transfer of basal stress to the unconnected region of the bed during the course of the events. No evidence for strong basal motion is seen in the instrument records for several weeks following the events, suggesting that the mechanical adjustments resulted in a stable configuration of basal stresses. This event illustrates how unstable situations can be quickly accommodated by mechanical adjustments at the glacier bed.
\end{abstract}

\section{INTRODUCTION}

Glacier motion is controlled to a great extent by the contact between ice and the underlying bed. If the bed is composed of saturated sediments, both sliding and sediment deformation can contribute to the total glacier motion. These two processes are strongly influenced by subglacial hydraulic conditions, as high subglacial pressures act both to decouple ice from the bed and to weaken the basal sediments.

At the beginning of the melt season, the subglacial drainage system is likely to be poorly developed and of low capacity. Rapid melting of the winter snowpack can introduce a substantial volume of meltwater into the drainage system, and if meltwater input exceeds the drainage-system capacity, hydraulic and mechanical instability can result. Instabilities caused by early-summer melting, often called "spring events" (Röthlisberger and Lang, 1987), have been widely observed and result in reorganization of the subglacial drainage system (e.g. Stone and Clarke, 1996; Gordon and others, 1998) or enhanced glacier motion (e.g. Iken and others, 1983; Harbor and others, 1997).

We present an analysis of instrument records taken during early summer 1995 at Trapridge Glacier, Yukon Territory, Canada. These records reveal a series of subglacial hydromechanical events that occurred following the establishment of a subglacial drainage system in the area. Pressure

\footnotetext{
* Present address: Department of Geography, University of
} California, Berkeley, California 94720, U.S.A. fluctuations in the drainage system weakened a region of the bed that was acting as a local pinning point and resulted in three episodes of strong basal motion (i.e. sliding and/or sediment deformation) on 11 June (day 162). Because these events occurred prior to our arrival at Trapridge Glacier in 1995, the records presented in this study are from instruments installed in previous field seasons.

\section{OBSERVATIONS}

Year-round measurements of subglacial conditions have been recorded at Trapridge Glacier (Fig. la and b) since 1988. One focus of these studies is to clarify the role that the subglacial water system plays in facilitating basal sliding and bed deformation (e.g. Blake and others, 1992; Fischer and Clarke, 1997, in press). Hot-water drilling allows rapid installation of instruments at the ice-bed interface, in the underlying till or within the glacier ice. Boreholes drilled to the glacier bed are classified as either connected or unconnected depending on whether communication with the subglacial water system is established. These designations do not necessarily correspond to the connection status at later times. After installation, instruments are connected to Campbell CR10 dataloggers, which are programmed to take measurements at intervals of 20 min during the winter. Fifty-six instruments were in operation on 11 June (day 162) 1995, and responses at the time of at least one of the three observed events are seen in the records for 42 of these sensors. These instruments were installed during a 5 year period spanning July $1990-$ July 1994, so it is necessary to account for their flow displacement. Glacier motion was 


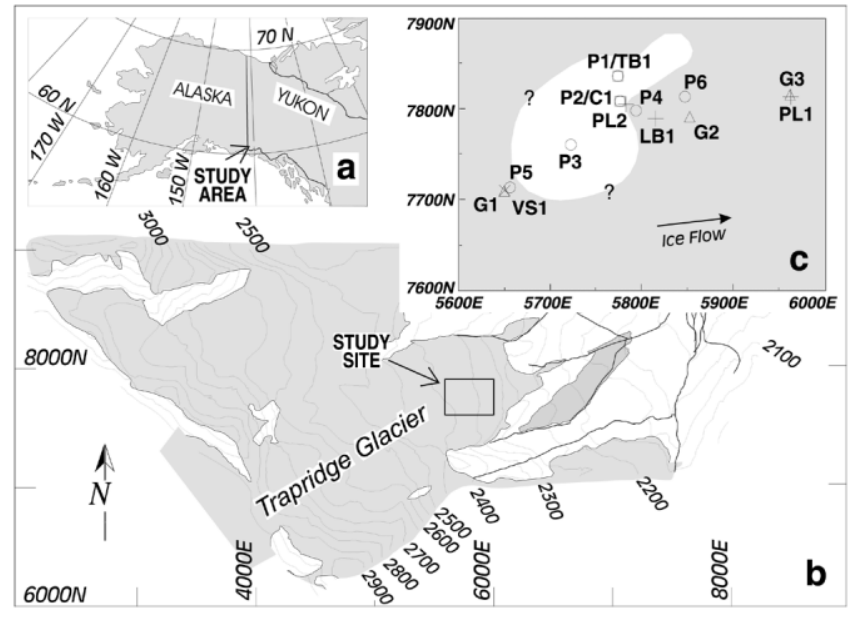

Fig. 1. Study area. (a) Location map, southwestern Yukon Territory. (b) Trapridge Glacier, showing location of instrument study. (c) Study site. Unshaded area indicates region of high interpreted connectivity; question marks denote poorly constrained boundaries. Instrument nomenclature: $P$, pressure transducer; $C$, conductivity sensor; TB, turbidity sensor; $P L$, ploughmeter; LB, load bolt; VS, vertical strain; $G$, geophone.

determined from annual surveys of flow markers, and sensor positions were adjusted assuming no vertical velocity gradient in the ice. Because ice deformation accounts for just $\sim 1 \mathrm{~m} \mathrm{a}^{-1}$ of the $\sim 30 \mathrm{~m} \mathrm{a}^{-1}$ total flow rate (unpublished data), this is a reasonable approximation. Corrected positions of instruments that exhibit responses at the time of the events are shown in Figure 2. In order to clarify discussion we present the records for 16 instruments that represent the range of responses observed during day 162. Corrected positions for these instruments are shown in Figure lc.

Figure 3a shows temperatures measured inside a datalogger enclosure during the period 1 May-30 June (day numbers 121-182) 1995 at Trapridge Glacier. Studies by Hock (1993) have shown that solar heating of non-ventilated temperature sensors can result in temperature measurements that exceed the true ambient air temperature by $>15^{\circ} \mathrm{C}$; the discrepancy for sealed logger enclosures could be larger. Because no air-temperature record is available, we will use the logger-enclosure temperature as a proxy for air temperature. Temperatures most relevant to this study are the minimum night-time temperatures, which are not expected to be significantly affected by solar heating. The logger-enclosure temperature record shows strong diurnal variations, with measured temperatures ranging from $-11^{\circ}$ to $+26^{\circ} \mathrm{C}$. Temperature fluctuations with time-scales of approximately 10-20 days are also apparent in the record. Minimum night-time temperatures remain above $0^{\circ} \mathrm{C}$ during days $131-133,145,160-167,170-173$ and 179-182.

Pressure transducer Pl (Fig. 3b) was installed during July 1994 in a borehole that connected at the time of drilling. The pressure record during days 121-159 alternates between two distinct modes: periods of high, steady pressures, with values close to the $\sim 60 \mathrm{~m}$ local flotation pressure head; and periods of high diurnal variability, which exhibit peak pressures greater than flotation and minimum night-time pressures lower than those recorded during high, stable periods. For clarity, we label these two behaviours "non-fluctuating" and "fluctuating" modes, respectively. Inspection of Figure 3 reveals a strong relationship between pressure modes and night-time temperatures, with fluctuating periods occurring in approximate conjunction with above-freezing night-time tempera-

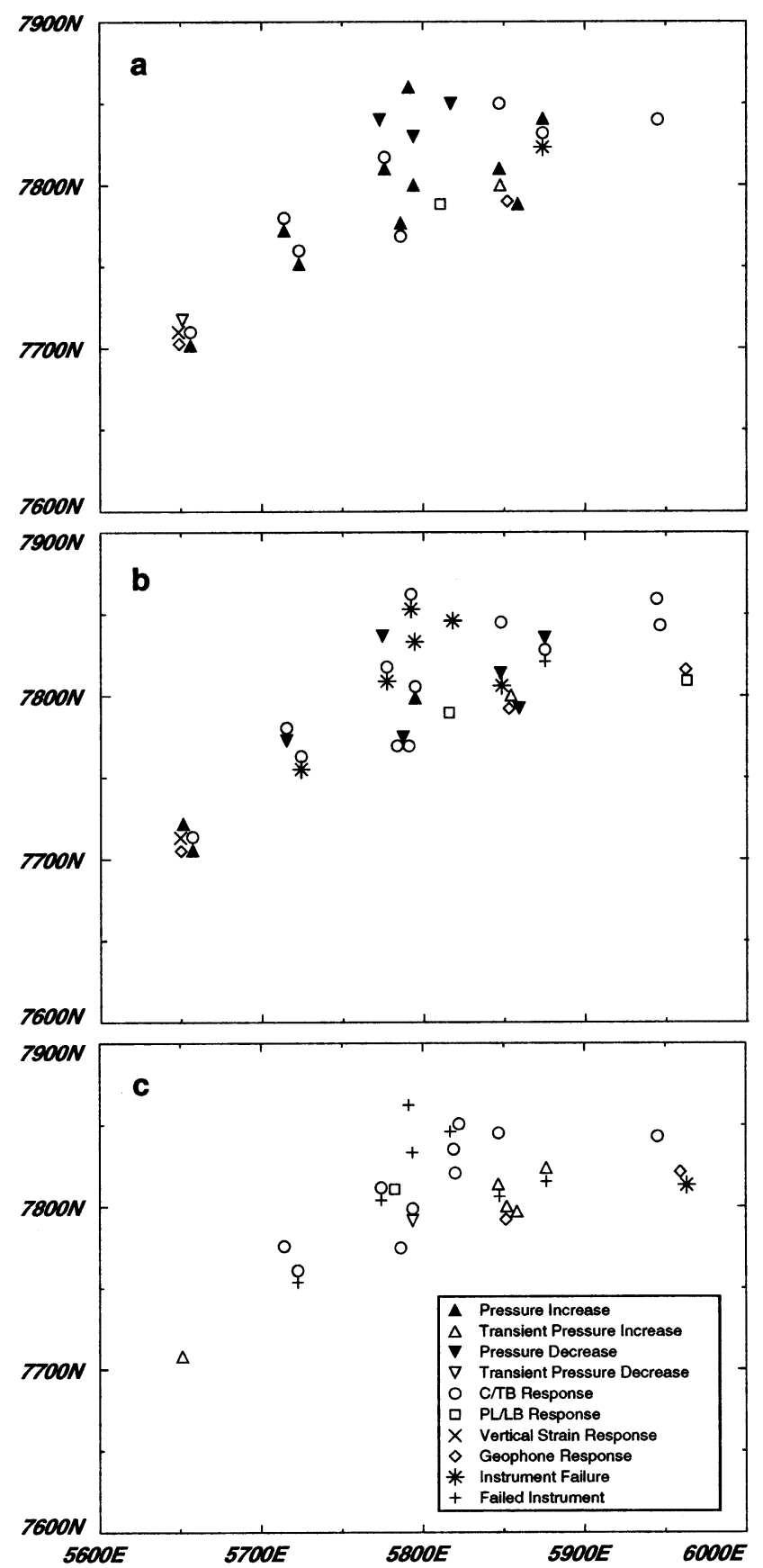

Fig. 2. Map view of instrument locations. Locations have been corrected for glacier flow, and overlapping symbols have been shifted slightly. (a) Instrument responses during event 1. (b) Instrument responses during event 2. (c) Instrument responses during event 3 .

tures: diurnal pressure fluctuations are recorded during days 129-137, 146-148, 160-167, 169-174 and 177-182 (shaded regions, Fig. 3). The third period of diurnal pressure fluctuations is punctuated by a $41.6 \mathrm{~m}$ pressure drop at $0820 \mathrm{~h}$ on day 162. Diurnal pressure variations continue uninterrupted following this drop, with negative-valued pressure minima indicated during days 164, 167, 170-172 and 178-179.

Transducers P2 and P3 (Fig. 3c and d) were installed in connected boreholes during July 1994. Both records show alternating fluctuating and non-fluctuating behaviour at the times observed in the record for Pl. Non-fluctuating pressures for P2 measure approximately $80 \%$ of the flotation value, while those for $\mathrm{P} 3$ register slightly greater than flotation. The timing of diurnal variations in both records closely matches those for Pl (shaded regions, Fig. 

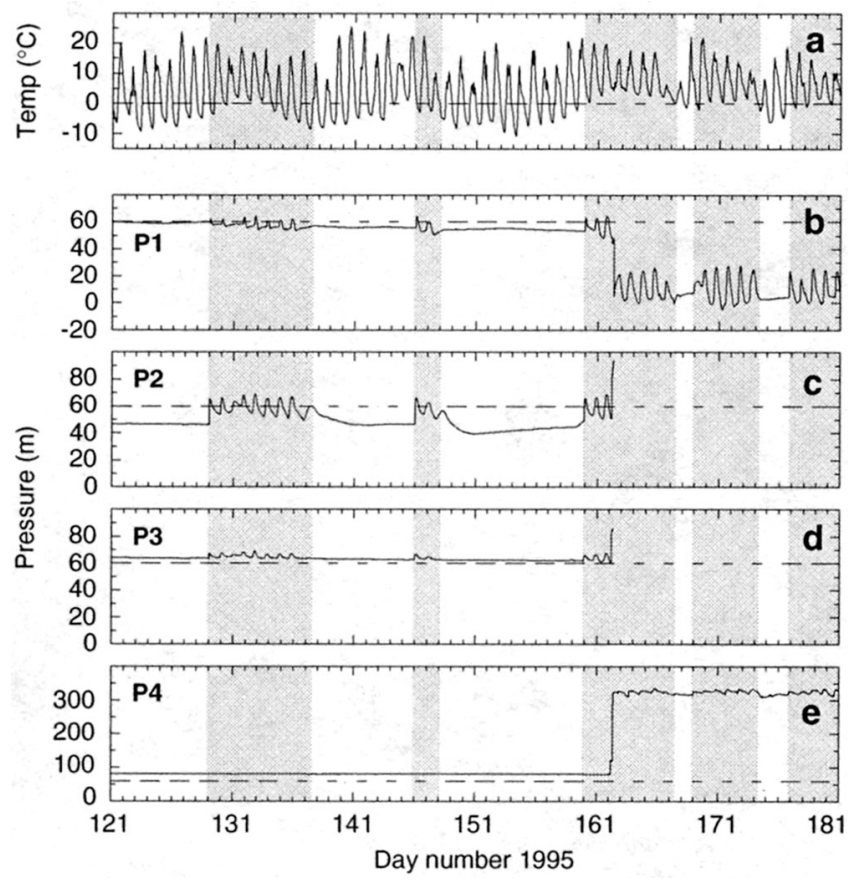

Fig. 3. Air-temperature and subglacial water-pressure records. Day 121 corresponds to 1 May 1995. Shaded regions indicate periods exhibiting diurnal pressure fluctuations. (a) Air-temperature record. (b) Water-pressure record for P1. Dashed horizontal line represents local flotation pressure. (c) Waterpressure record for P2. (d) Water-pressure record for P3. (e) Water-pressure record for P4 (note change of scale).

3), and similar peak pressure values are indicated in all three transducer records during diurnal fluctuations. Both P2 and P3 fail at $0820 \mathrm{~h}$ on day 162 , coincident with the $41.6 \mathrm{~m}$ pressure drop in the record for $\mathrm{Pl}$.

Transducer P4 (Fig. 3e) was installed in July 1993 in a borehole that connected at the time of drilling. Steady pressures are indicated for the first 39 record days, with values of approximately $135 \%$ of the local flotation value. Diurnal pressure fluctuations, out of phase with those in the records for $\mathrm{P} 1-\mathrm{P} 3$ and with amplitudes of $\sim 0.8 \mathrm{~m}$, begin on day 160 (not visible in Fig. 3e due to the large vertical scale). Abrupt pressure increases of 41.1 and $201.8 \mathrm{~m}$ are recorded at 0500 and $0820 \mathrm{~h}$, respectively, on day 162. Indicated pressures following these changes measure $>300 \mathrm{~m}$.

Figure 4 details the pressure record for three sensors on day 162. Sensor P1 (Fig. 4a) registers a decrease of $4.3 \mathrm{~m}$ at $0500 \mathrm{~h}$, immediately following the beginning of the diurnal pressure rise. This decrease is followed by the $41.6 \mathrm{~m}$ drop at $0820 \mathrm{~h}$ seen in Figure 3b. The pressure record for transducer P5 (Fig. 4b), which was installed in an unconnected borehole in July 1993, shows small pressure increases of 1.1 and $0.7 \mathrm{~m}$ coinciding with the drops recorded by $\mathrm{P} 1$ at 0500 and 0820 h. The record for transducer P6 (Fig. 4c), installed in July 1992 in an unconnected borehole, also shows pressure changes at these times: an increase of $1.9 \mathrm{~m}$ at $0500 \mathrm{~h}$ is followed by a decrease of $1.6 \mathrm{~m}$ at $0820 \mathrm{~h}$. In addition, a transient pressure increase of $10.9 \mathrm{~m}$ is recorded at $1820 \mathrm{~h}$. Many instrument records exhibit responses within one 20 min sampling interval of these times, suggesting the occurrence of a series of subglacial events during day 162 . Hereafter, we designate the events at 0500, 0820 and $1820 \mathrm{~h}$ as events 1,2 and 3 .

Clock drift during the winter months can result in discrepancies as large as 6 min between loggers, and instrument

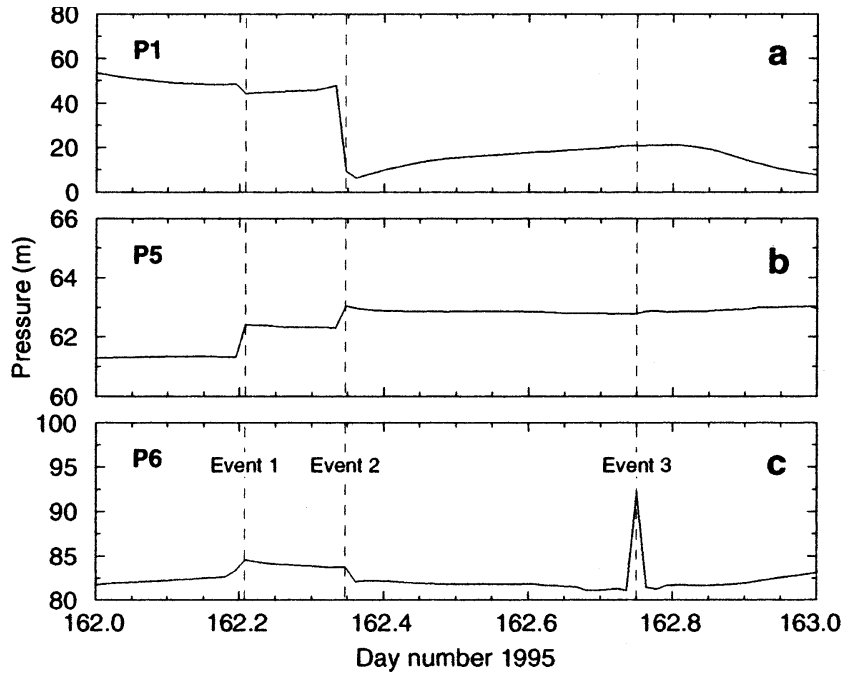

Fig. 4. Detailed pressure records. Day 162 corresponds to 11 June 1995. (a) Transducer P1. (b) Transducer P5. (c) Transducer $P 6$.

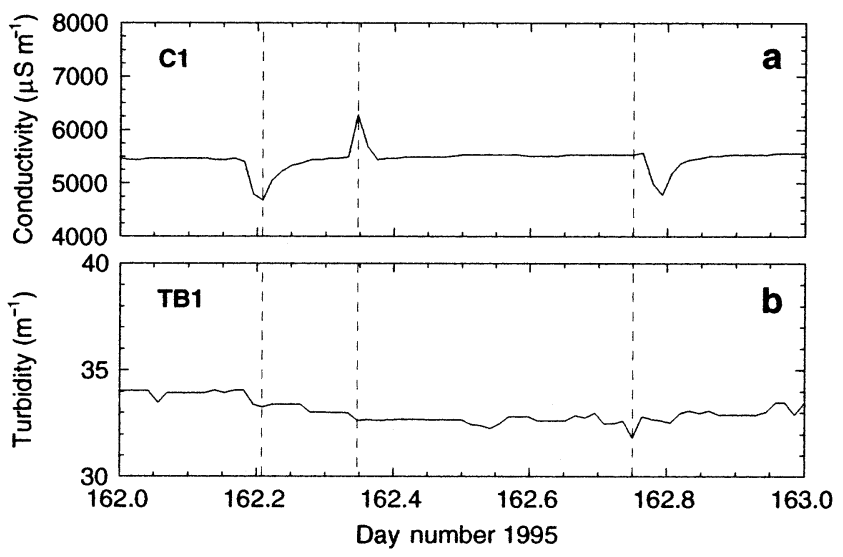

Fig. 5. Hydrology-sensor records. Dashed vertical lines at 0500,0820 and 1820 hrepresent events 1-3. ( a) Conductivity sensor C1. (b) Turbidity sensor TB1.

responses to events that occur within this measurement window will be distributed over two sampling intervals. Several instrument records demonstrate responses to events 2 and 3 that lag the event timing by one sampling interval. Although it is possible that these lags reflect a series of strong mechanical adjustments around the time of the events, they are equally attributable to clock drift. The lags do not appear to be correlated to instrument location, suggesting that the large mechanical forcings recorded during the events affected the entire study area simultaneously.

Figure 5 illustrates typical event responses for conductivity and turbidity sensors (Stone and others, 1993) during day 162. Dashed vertical lines represent the timing of events $1-3$. Conductivity sensor Cl (Fig. 5a) was installed in the same borehole as transducer P2 (Fig. 3c). Negative transient responses were recorded at event 1 and immediately following event 3, and a positive transient was noted at event 2 . Responses to the three events are of comparable magnitude $\left(\sim 800 \mu \mathrm{S} \mathrm{m}^{-1}\right)$, and a background conductivity value of $5400 \mu \mathrm{S} \mathrm{m}^{-1}$ is re-established within $180 \mathrm{~min}$ of each event. Turbidity sensor TB1 (Fig. 5b) was installed in the same borehole as sensor Pl (Figs $3 \mathrm{~b}$ and $4 \mathrm{a}$ ). Very small responses were recorded during the events, with a $0.8 \%$ drop at event 1 and a transient change of $-0.9 \%$ at event 3 superimposed onto the slight $(\sim 2 \%)$ diurnal signal. 


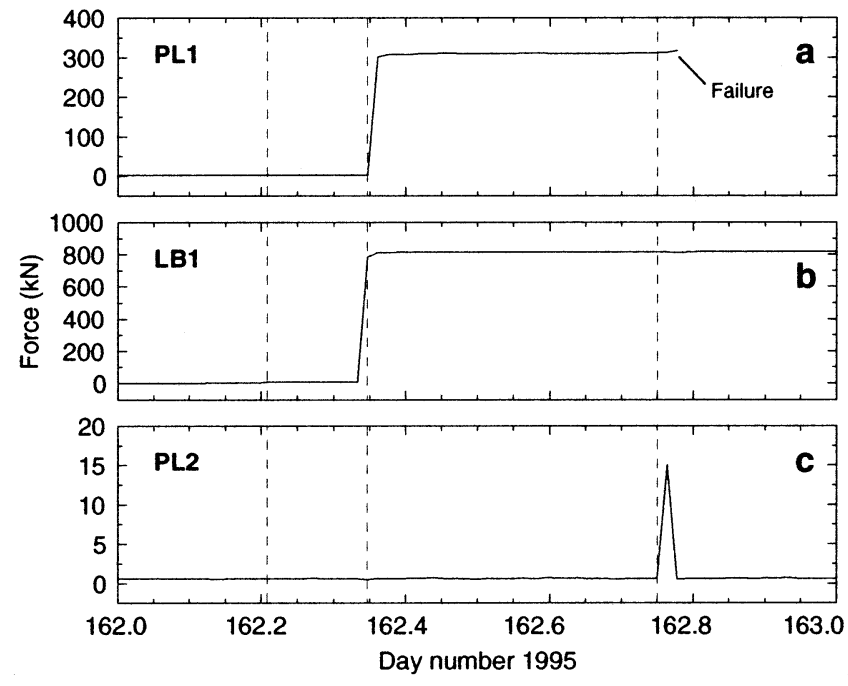

Fig. 6. Mechanical-sensor records. Dashed vertical lines at 0500, 0820 and 1820 h represent events 1-3. (a) Ploughmeter PL1. (b) Load-bolt sensor LB1. (c) Ploughmeter PL2.

Records during day 162 for three instruments that measure mechanical forcings in the glacier bed are shown in Figure 6. Ploughmeter PLl (Fig. 6a) was installed in July 1992. While no response is evident at event 1 , measured force values increased from $1.9 \mathrm{kN}$ to $310 \mathrm{kN}$ during event 2 . High, steady values were measured until sensor failure occurs immediately following event 3. Load bolt LBl (Fig. 6b) was installed in July 1993. The force acting on the instrument increases from $2.3 \mathrm{kN}$ to $9.0 \mathrm{kN}$ at event 1 (this change is difficult to see given the large vertical scale) and then to $813 \mathrm{kN}$ at event 2. This high value is measured for the remainder of the record, with no further response seen at event 3. The record for ploughmeter PL2 (Fig. 6c), installed in July 1994, shows a steady force value of $\sim 0.6 \mathrm{kN}$ through most of day 162 . No response is evident at event 1 or 2 , but a transient increase of $15.1 \mathrm{kN}$ is seen immediately following event 3 .

Figure 7 shows the record during days 161-164 for verticalstrain sensor VS1, which was installed approximately $15 \mathrm{~m}$ below the ice surface during July 1992. Vertical-strain values increase steadily through the first part of the record; this trend is consistent with increasing values recorded over the previous 20 days (not shown). Maximum vertical extension of the ice occurs immediately prior to event 1 , and constant strain values are measured between events 1 and 2. A drop of $\sim 2.64 \mathrm{~mm} \mathrm{~m}^{-1}$ in vertical strain occurs at event 2 , with no further response seen at event 3 . Following the events, verticalstrain values remain constant for 8.5 days before they begin increasing again. Details of the construction and theory of ploughmeter, load-bolt and vertical-strain sensors can be found in Fischer and Clarke (1994), Iverson and others (1994) and Harrison and others (1993), respectively.

Records for three geophones installed in July 1990 are shown for day 162 (Fig. 8). A generally down-glacier progression of high count rates is apparent in the records, with elevated count rates spanning a several-hour period at each event. Geophone Gl (Fig. 8a), located approximately $0.9 \mathrm{~m}$ from VSl, is furthest up-glacier of the three geophones. Its record shows counts as early as $3.3 \mathrm{~h}$ before event 1 , with a broad peak of $2.90 \mathrm{~min}^{-1}$ occurring at the time of the event. Count rates between events 1 and 2 average $0.90 \mathrm{~min}^{-1}$ and increase to $1.40 \mathrm{~min}^{-1}$ during event 2 . Following event 2 , no further counts are noted for the remainder of the day. The record for geophone G2 (Fig. 8b), located in the middle of

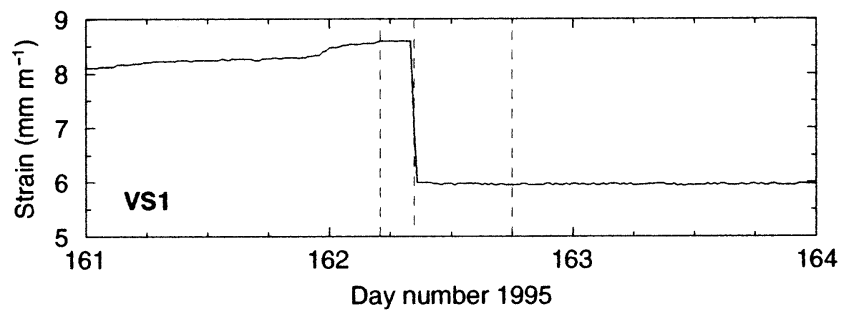

Fig. 7.Vertical-strain record during days 161-164 (10-12 June 1995). Dashed vertical lines at 0500, 0820 and 1820 h during day 162 represent events $1-3$.

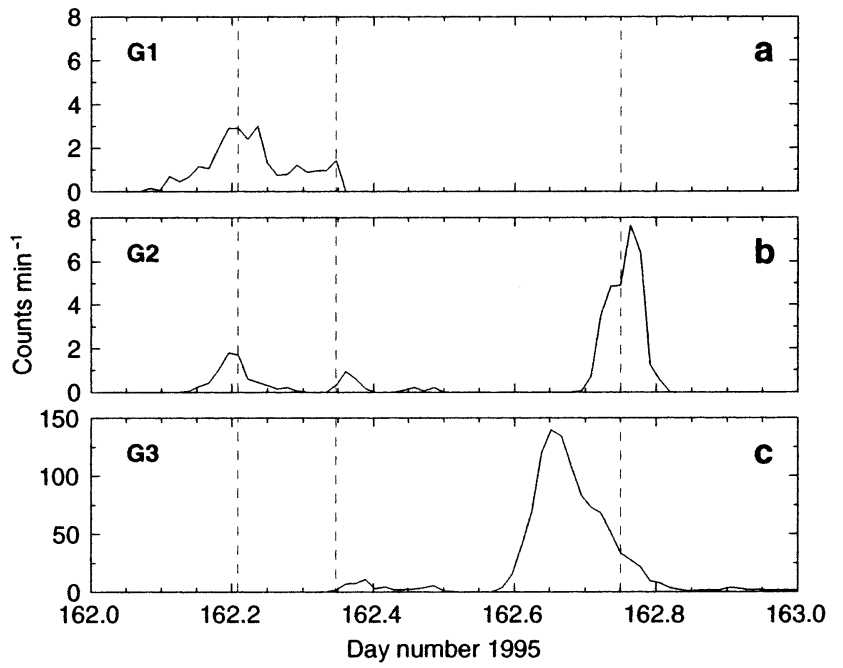

Fig. 8. Geophone records during 11 fune 1995. Plotted are the number of "icequake" events per minute; the timing and magnitude of individual events are not recorded. Dashed vertical lines at 0500, 0820 and $1820 \mathrm{~h}$ represent events $1-3$.

the study area, shows peak rates of $1.80 \mathrm{~min}^{-1}$ immediately prior to event 1 and $0.95 \mathrm{~min}^{-1}$ during event 2. Elevated count rates are measured during a $2.67 \mathrm{~h}$ period spanning event 3, with a peak of $7.65 \mathrm{~min}^{-1}$ immediately following the time of the event. Geophone G3 (Fig. 8c) is located at the lower end of the study area. No counts are evident until event 2; a peak count rate of $10.75 \mathrm{~min}^{-1}$ is observed $1 \mathrm{~h}$ later. Extremely high count rates are recorded during a $7 \mathrm{~h}$ period spanning event 3, with a peak rate of $139.8 \mathrm{~min}^{-1}$ indicated at $1540 \mathrm{~h}$. The count rate declines to $27.9 \mathrm{~min}^{-1}$ at event 3 .

\section{INTERPRETATION AND DISGUSSION}

The instrument records presented in Figures 3-8 show evidence for both hydrological and mechanical responses during three subglacial events on day 162. These events occur soon after hydraulic connection is re-established in the region, suggesting that changes in drainage-system morphology altered both the hydrological and mechanical properties of the bed (e.g. Fischer and Clarke, in press). In the following sections we present an interpretation of the hydrological and mechanical responses recorded during the events.

\section{Hydrological response}

The high, steady pressures seen in the first part of the records for transducers $\mathrm{Pl}-\mathrm{P} 3$ (Fig. 3b-d) are typical of winter pressure records and indicate a low-volume, poorly connected subglacial hydraulic system (e.g. Stone, 1993). In contrast, per- 


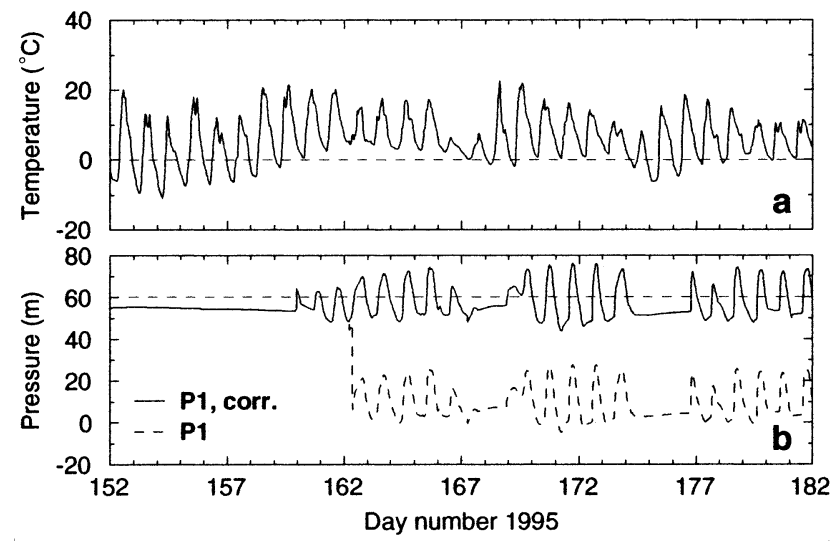

Fig. 9. Air-temperature and corrected subglacial water-pressure records. Day 152 corresponds to 1 June 1995. (a) Air-temperature record. (b) Corrected pressure record for P1. Uncorrected record (dashed) is shown for comparison. Horizontal dashed line represents the local flotation pressure.

iods of diurnal pressure fluctuations (shaded regions) are characteristic of well-connected summer drainage systems. Pressure excursions during these periods are driven by variations in the flux of meltwater reaching the glacier bed as the daily melt rate peaks and ebbs. The records for $\mathrm{P} 1-\mathrm{P} 3$ indicate repeated establishment and shut-down of a connected drainage system. In total, such connections are found in the records for eight pressure transducers, indicating repeated hydraulic connections over a $\sim 20000 \mathrm{~m}^{2}$ portion of the instrumented region during these periods. This connected region is shown in Figure lc (unshaded area). Periods of hydraulic connection in the records for P1-P3 (Fig. 3a-c) coincide with warm night-time temperatures, suggesting rapid, sustained melting of the winter snowpack during these times. Such vigorous early-season melting can place a substantial volume of water into the subglacial drainage system, which is likely to be poorly developed at the beginning of summer. If the input of meltwater exceeds the capacity of the drainage system to remove it, hydrological and mechanical instability can result (e.g. Stone, 1993; Jansson, 1995; Stone and Clarke, 1996; Gordon and others, 1998).

Minimum night-time pressures measured during fluctuating periods exhibit values that are lower than the pressures recorded during stable non-fluctuating periods (Fig. 9b). This behaviour demonstrates the higher transport capacity of connected drainage systems, which allow greater evacuation of basal water and thus lower night-time pressures. The records also show that the drainage system actively adjusts to variations in meltwater input, as low night-time pressures generally correspond to high daytime temperatures. This is not surprising, as increased drainage capacity during periods of high meltwater flux would result in the depression of both daytime and night-time pressures. This relation is most clearly evident during days 170-177 (Fig. 9a and b). Decreasing daytime temperatures seen in days $170-174$ are accompanied by increasing minimum night-time pressures, and decreasing meltwater input during this period leads to closure of the connected system. This results in decreased drainage capacity and higher nighttime pressure minima. The system switches to an isolated nonfluctuating mode when night-time temperatures dip below freezing on day 174 and the meltwater flux drops below a threshold value. Hydraulic connection is re-established on day 176 with the return of higher temperatures and increased meltwater input.
It is not clear how the drainage-system capacity changes in response to changes in meltwater input. Variations in minimum night-time pressures show that although adjustments occur rapidly enough to accommodate changes in daily meltwater input, the adjustments are not immediately reversible. One plausible mechanism by which the drainage system can adjust its transport capacity is the incorporation of additional basal area during periods of high meltwater input. This process could be facilitated by hydraulic jacking (ice--bed separation promoted by high water pressures), which would allow rapid flooding of the drainage-system margins (Murray and Clarke, 1995; Gordon and others, 1998). Evidence for hydraulic jacking is seen in the records for several pressure transducers, including P4-P6 (Figs 3e and 4b and c), located on the periphery of the well-connected region (Fig. 1c). These records exhibit low-amplitude diurnal fluctuations that are out of phase with those of $\mathrm{Pl}$, indicating the transfer of mechanical support of ice overburden from the unconnected region as water pressure varies in the connected system (Murray and Clarke, 1995). Flooding of the drainage system margins would increase the hydraulic transmissivity there and permit greater meltwater transport. Subsequent reductions in meltwater flux would allow the margins to lose hydraulic connection with the drainage system, resulting in decreased transport capacity, lower hydraulic transmissivity and higher night-time pressure minima (Hubbard and others, 1995; Alley, 1996).

Records for 14 transducers exhibit step pressure changes at the time of events 1 and 2. Rather than suggesting widespread hydrological changes, however, these records could instead indicate episodes of mechanical instability. It is likely that changes in the subglacial drainage system sufficient to precipitate the $41.6 \mathrm{~m}$ drop observed in the record for Pl (Figs $3 \mathrm{~b}$ and $4 \mathrm{a}$ ) would also lead to changes in the response of the system to pressure variations. Instead, the record for $\mathrm{Pl}$ exhibits consistent behaviour both before and after the indicated drops. Figure $9 \mathrm{~b}$ shows a pressure record for $\mathrm{Pl}$ during days 152-182 in which the abrupt drops at 0500 and $0820 \mathrm{~h}$ have been removed (solid line). The corrected record shows diurnal variations, with daytime pressures greater than the local flotation value, and night-time minima of 44-50 m. Days 168 and 174-176, during which diurnal variations are absent, exhibit pressures similar to the steady non-fluctuating pressures measured prior to day 159. After correction, pre- and post-event pressure-signal characteristics are consistent during both non-fluctuating and fluctuating modes. In addition, removal of the pressure drops eliminates the negative pressure values in the uncorrected record (dashed line) during days 164, 167, 170-172 and 178-179. These negative values are too large to be attributable to errors in calibration or installation. Further evidence for transducer failure is found in the record for P4 (Fig. 3e). Pressures following the $201.6 \mathrm{~m}$ increase at event 2 measure greater than five times the local overburden pressure, values too high to be maintained subglacially. These records thus provide good evidence that the abrupt pressure changes seen in several transducer records are caused by transducer malfunction rather than by actual changes in subglacial hydrological conditions. Studies by Kavanaugh and Clarke (2000) show that extreme pressure pulses, generated by abrupt ice motion, can damage the measurement mechanism of pressure transducers. This damage produces a calibration shift that appears in field records as an abrupt pressure change or, if the pressure pulse is sufficiently large, device failure. This mode of transducer malfunction can thus account for both 
the unrealistic pressure values observed in the records for $\mathrm{Pl}$ and $\mathrm{P} 4$ and the failure of seven pressure transducers (including P2 and P3; Fig. 3c and d) during events 1 and 2.

Evidence for a transient pressure pulse at the time of event 3 is seen in the record for transducer P6 (Fig. 4c). Although the indicated pulse magnitude is too small to cause sensor damage, it is not certain that the maximum pulse pressure was captured during measurement. Additionally, spatial variations in drainage-system properties could act to locally modulate the pulse magnitude. Pressure transients are seen in the records for several other transducers at the time of the events. Evidence for abrupt glacier motion is seen in ploughmeter and load-bolt records at the time of the events and will be discussed in the following section.

Although many of the large pressure changes can be clearly ascribed to sensor damage, the veracity of smaller changes is more difficult to determine. Transducers P5 and P6 (Fig. 4b and c) are located outside the region of high connectivity shown in Figure 1 and exhibit unconnected behaviour during the time of the events. It is unclear whether the small pressure changes noted at events 1 and 2 in these records result from sensor damage or from true, if minor, adjustments in water pressure at the location of the instruments. Similarly, the small change at event 1 in the record for Pl (Fig. 4a) could represent a real shift. In either case, the minor pressure adjustments noted at the time of the events in these and other transducer records are too small to indicate significant changes in drainage-system morphology.

While extreme pressure pulses can result in pressuretransducer malfunction, other instruments are insensitive to them. Because of this, pressure pulses selectively damage pressure transducers without affecting other instruments, including those installed in the same borehole and sharing a common signal wire (Kavanaugh and Clarke, 2000). Pressure transducer P2 (Fig. 3c), which fails at event 2, was installed in the same borehole with $\mathrm{Cl}$ (Fig. 5a); the conductivity sensor is undamaged. In total, seven pressure transducers fail during the events, but none of the instruments installed in common holes fails at these times. This selective device failure argues against several common failure mechanisms, including wire breakage and crushing of the transducer, and further supports the attribution of transducer failure to large pressure pulses at the time of the events.

In contrast with the large pressure signals recorded during the events, records for turbidity and conductivity sensors (Fig. 5) show only minor responses. The record for $\mathrm{Cl}$ exhibits transient responses at all three events, returning to a stable background value following each event. These features suggest the disturbance and subsequent re-establishment of a stratified conductivity structure within the borehole (personal communication from G. Oldenborger, 2000) caused by abrupt glacier motion that forces water into underlying sediments (events 1 and 3) or expels water from these sediments (event 2), displacing the conductivity structure from its equilibrium state. The responses in the record for TB1 (Fig. 5b) at events 1 and 3 are too small to suggest lasting changes in drainage patterns and give little evidence for substantial movement of basal water during any of the events. Similarly, after removal of the large damage-induced pressure changes in the records for Pl and other transducers, little indication of lasting change is present in the pressure records. Hydraulic responses during the events thus appear to have been largely transient, with little evidence for morphological changes in the subglacial drainage system.
These behaviours differ significantly from those observed during both a 1993 spring event recorded at Haut Glacier d'Arolla, Switzerland (Gordon and others, 1998), and a 1990 event at Trapridge Glacier (Stone and Clarke, 1996). In both of these cases, the drainage system switched from a low-capacity, non-fluctuating mode to a high-capacity, diurnally varying one during the event. These studies indicate that the input of spring meltwater can yield varying responses, not only from glacier to glacier but also from year to year at a given glacier.

\section{Mechanical response}

The records for PL1, LB1 and PL2 (Fig. 6a-c) indicate significant changes in mechanical forcing at the time of the events. Both the magnitude and rapidity of these changes suggests that they result from strong basal motion (i.e. sliding and/or sediment deformation). Yet while an instrument response to basal motion would be expected if till behaviour is linear or mildly non-linear (as suggested by Boulton and Hindmarsh, 1987), it is not clear whether such a response would be expected if subglacial till behaves as a Coulomb-plastic material. Coulomb-plastic behaviour has been suggested by recent laboratory (e.g. Iverson and others, 1998; Tulaczyk and others, 2000), field (e.g. Hooke and others, 1997) and modelling studies (Kavanaugh, 2000). For viscous tills, any change in basal velocity (and therefore the rate at which the instrument is pulled through the sediments) would result in a corresponding change in force acting upon the instrument. In contrast, the force measured by a ploughmeter or load bolt in Coulomb-plastic till should depend only on the pore-water pressure within the sediments and not on the basal velocity.

To explain transient responses to rapid basal motion in Coulomb-plastic tills, we need to consider dilatancy, or expansion under shear. This behaviour has been observed in overconsolidated tills (e.g. Boulton and others, 1974; Clarke, 1987). Overconsolidation is likely to be produced by pressure variations in tills that have not been significantly sheared for a time (Iverson and others, 1998). Subsequent shearing of an overconsolidated till by ploughmeter or loadbolt motion could produce a dilatant response, resulting in a drop in pore-water pressure that in turn strengthens the till. Such strengthening is called "dilatancy hardening" and has been observed in laboratory studies (e.g. Iverson and others, 1998). In general, basal motion occurs slowly enough that the pore-water pressure in the disturbed sediments has time to equilibrate with the surrounding pressures. Rapid instrument motion, however, can create dilatancy rates that are large relative to pore-water flow and hence produce appreciable dilatancy strengthening of the till immediately surrounding the instrument. The transient response recorded by PL2 at event 3 (Fig. 6c) is of short duration, indicating rapid equalization of pore-water pressures with the surrounding values. Calculations show that hydraulic diffusivities greater than $10^{-6}$ to $10^{-4} \mathrm{~m}^{2} \mathrm{~s}^{-1}$ are required to explain the rapid decay of dilatancy strengthening suggested by the instrument records. These values are in reasonable agreement with values of hydraulic diffusivity obtained in laboratory measurements (e.g. Iverson and others, 1997) and field studies (e.g. Stone and others, 1993; Fischer and others, 1998). It should be noted that a secondary effect that could counteract dilatancy hardening has been observed in laboratory experiments. Rapid instrument motion can also result in till compression and 
hence an increase in pore-water pressures in front of the sensor. These excess pore pressures have the potential to significantly reduce the strength of the till ahead of the sensor (e.g. Iverson and others, 1994; Iverson, 1999). While it is unclear how much this excess pore-pressure weakening affects dilatancy hardening, these instrument records suggest that dilatancy hardening is the dominant effect.

In contrast with the transient response of PL2, the force records for PL1 and LB1 (Fig. 6a and b) exhibit step increases at the time of event 2; LBl also shows a step increase at event 1 . The dilatancy hardening suggested in the record for PL2 (Fig. 6c) is expected to be a short-lived effect, as pore-water pressures in the till around the instrument will tend to equalize with surrounding values. The high sustained forcings reported by PLl and LB1, at 310 and $813 \mathrm{kN}$, measure 10-100 times greater than typical peak forcings recorded at Trapridge Glacier and are therefore suggestive of permanent damage sustained during the events. Strong basal motion, coupled with sufficient dilatancy hardening, could have permanently bent the steel rod in ploughmeter PLl during event 2. This bend would produce an apparent offset in measured force analogous to the changes seen in pressure-transducer records. Attribution to sensor damage is also suggested by the failure of PL1 during event 3. The record for LBl can be explained by similar damage.

Records for vertical-strain sensors are used to infer longitudinal compression (increasing vertical-strain values) or extension (decreasing values) of the glacier. The record for VSl indicates continuous longitudinal compression prior to the event (Fig. 7); similar compression was recorded during the preceding 20 days. The rate of compression during this period is typical of strain-gauge records in the study area (unpublished data). Slightly elevated strain values are observed between the beginning of day 162 and event 1 , and maximum vertical strain is reached immediately prior to the event. The constant-strain value recorded between events 1 and 2 indicates no further longitudinal compression during this period, and the large drop at event 2 indicates a decrease in vertical strain equal to the net extension of the previous 288 days. This substantial decrease suggests significant longitudinal extension at the time of event 2, perhaps accompanied by crevassing in the vicinity of the sensor (Harrison and others, 1993). The record for VS1 is thus consistent with the evidence for strong basal motion seen in ploughmeter and load-bolt records. There is no indication of instrument malfunction at this time. Five other vertical-strain sensors were in operation on day 162, but none shows any response, suggesting that longitudinal extension of the ice occurred only locally. This contrasts with behaviours observed during short-term motion events recorded at Findelengletscher, Switzerland (Iken and Bindschadler, 1986), and "mini-surges" observed at Variegated Glacier, Alaska, U.S.A. (Kamb and Engelhardt, 1987). During each of these events, a zone of compression and subsequent extension passed down-glacier as a wave. Wave velocities indicated in these studies range between $\sim 50-180 \mathrm{~m} \mathrm{~h}^{-1}$ during three events at Findelengletscher and $\sim 300 \mathrm{~m} \mathrm{~h}^{-1}$ at Variegated Glacier. All of these strain events were accompanied by a wave of high subglacial water pressure that travelled down-glacier. No evidence for such a pressure wave during the events presented here is seen in transducer records.

Geophones respond to a variety of sources, such as ice fracture and basal slippage. Geophone records can therefore yield information about stress transients in the glacier, as these sources typically involve some failure mechanism and are thus focused where rapid changes in the stress field occur. Geophone G1 (Fig. 8a) is located slightly up-glacier from the large connected region shown in Figure 1c. Elevated count rates during a $7 \mathrm{~h}$ period spanning events 1 and 2 indicate that mechanical adjustments occurred throughout this period. The record for geophone G2 (Fig. 8b), which is located slightly down-glacier of the connected region, also shows elevated count rates during events 1 and 2. These records indicate significant changes in the state of stress in the connected region (Fig. 1c) between geophones Gl and G2 during this period. Similarly, the extremely high count rates in the record for G3 (Fig. 8c) suggest changes in the stress field below the connected region during a 7 hour period centred upon event 3. This down-glacier progression of high count rates in the geophone records indicates the migration of a region of high stress over the course of the events. This region likely represents a local "sticky spot", or area in which the basal shear stress is concentrated (Alley, 1993). Migration of this sticky spot will be discussed in the following section.

\section{Glacier response}

Because sediment strength is strongly dependent on porewater pressure, diurnal pressure fluctuations within the subglacial drainage system result in variations in sediment strength over much of the bed. In addition, high drainagesystem pressures can weaken coupling of the ice-bed interface and thus facilitate basal sliding. Through these processes, diurnal pressure fluctuations drive a cyclic transfer of shear stress between connected and unconnected regions of the bed (e.g. Alley, 1996; Iverson and others, 1999; Kavanaugh, 2000; Fischer and Clarke, in press). It is therefore likely that the establishment of a subglacial drainage system prior to the events resulted in significant changes in the distribution of basal stresses in the region.

Low drainage-system pressures in the hours preceding event 1 could have resulted in stiffening of sediments and increased ice-bed coupling in the connected region, creating a local sticky spot. It is not clear from instrument records whether this sticky spot existed prior to hydraulic connection (and was subsequently strengthened by the low system pressures) or if it was created by overconsolidation of sediments in the connected region by the diurnal pressure variations of days 159-161 (cf. Iverson and others, 1998). The increased vertical-strain values in the record for VS1 (Fig. 7) suggest that stresses were concentrated on this region in the early hours of day 162. This concentration could also be reflected by the counts registered by geophones G1 and G2 (Fig. 8a and b) prior to event 1. System pressures at this time are near the lowest point in the diurnal cycle, so it is likely that the counts reflect shearing of the basal sediments rather than glacier sliding (Kavanaugh, 2000). Because the effective listening range of a geophone varies with icequake magnitude, it is not possible to determine the proximity of an icequake source relative to the geophone placement. The true location and extent of a nearby sticky spot, therefore, cannot be determined from geophone records. Figure 10b illustrates one possible configuration at the time of event 1 ; other plausible sticky-spot configurations are certainly possible. The sticky spot, represented by the 


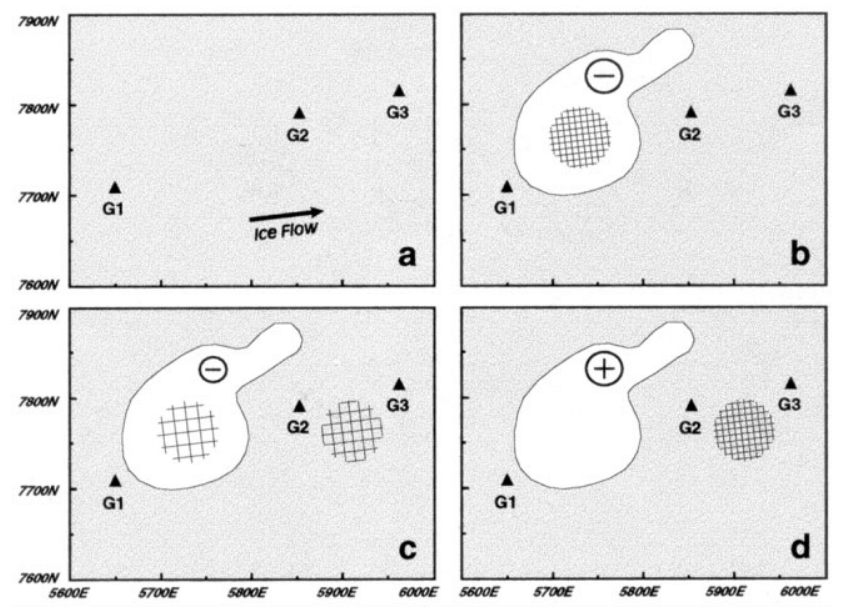

Fig. 10. Migration of local "sticky spot" during events. Shaded areas represent hydraulically-unconnected regions; unshaded areas represent region of high hydraulic connectivity. Crosshatched areas represent possible location(s) of sticky spot. Locations for geophones G1-G3 are shown. (a) Prior to hydraulic connection. (b) Possible sticky-spot configuration prior to and during event 1. (c) Possible sticky-spot configuration during events 2 and 3. (d) Possible sticky-spot configuration following event 3.

cross-hatched area, is located within the connected region of the bed (unshaded area). Shading represents hydraulicallyunconnected regions of the bed. Subsequent increases in drainage-system pressure would facilitate both sediment deformation and glacier sliding in the connected region, making this sticky-spot configuration inherently unstable.

Event 1 occurs at $0500 \mathrm{~h}$, immediately following the onset of the diurnal pressure rise of day 162. Basal motion during the event is indicated by the force increase in the record for sensor LBl (Fig. 6b) and by the failure of one pressure transducer (Fig. 2a). This transducer was installed in the basal sediments in order to measure pore-water pressures, making it particularly susceptible to damage during glacier motion. The timing of the event indicates a high degree of instability in this part of the glacier: although both sediment strength and ice--bed coupling are expected to be at their maximum at this time, failure of the bed occurred after only a minor increase in system pressure. Because the events occurred prior to our arrival at Trapridge Glacier, no survey data exist during the time of the events. Similarly, no tilt cells or slidometers (Blake and others, 1992, 1994), used to measure glacier sliding and sediment deformation, were in operation at this time. It is thus not possible to determine the true magnitude of glacier motion during the events.

As noted above, it is not clear whether minor adjustments in the records for several pressure transducers are due to transducer damage or to actual changes in basal water pressure resulting from mechanical adjustments at the glacier bed. If real, small pressure changes similar to that in the record for Pl (Fig. 4a) could have mixed water within the borehole and brought lower-conductivity water in contact with sensor Cl (Fig. 5a); responses at events 2 and 3 in the records for $\mathrm{Pl}$ and $\mathrm{Cl}$ could be similarly explained. The transient responses by conductivity and turbidity sensors during the event show no evidence for significant or lasting changes in the drainage system during the event. Steady values in the record for VSl (Fig. 7) following the event suggest that longi- tudinal compression in this region of the glacier was temporarily halted by basal motion.

Event 2 occurs at $0820 \mathrm{~h}$ following an increase in drainage-system pressures; locations of instruments that exhibit responses at this time are shown in Figure $2 b$. Although system pressures at the time of the event are lower than those measured in the unconnected region, increasing system pressures likely resulted in the weakening of sediments in the sticky spot and precipitated a second episode of vigorous basal motion. Although no evidence for sediment weakening is seen in the records for PL1, LBl or PL2 (Fig. 6a-c), these sensors were located in hydraulically unconnected regions where no change would be expected. No mechanical instruments were operating in the connected region at the time of the events. Basal motion during event 2 is evidenced by large force responses in the records for PL1 and LB1 (Fig. 6a and b) and by substantial longitudinal extension in the record for VS1 (Fig. 7). Large step changes seen in the records for four pressure transducers, as well as the failure of six transducers (Fig. 2b), indicate pervasive pressuretransducer damage during the event. This damage is likely due to extreme pressure pulses generated by the strong basal motion. In general, pressure changes associated with event 2 are of greater magnitude than those recorded during event 1 , indicating that pulses were correspondingly larger. This is consistent with evidence for strong basal motion presented in the records for PL1, LBl and VSl. The minor responses noted in the records for conductivity and turbidity sensors (Fig. 2b) result from glacier motion and, as for event 1 , do not represent lasting changes in drainage.

The period of elevated count rates in the record for Gl (Fig. 8a) ends at event 2, and no further counts were recorded for the remainder of the day. In contrast, counts first appear in the record for G3 immediately following event 2 (Fig. 8c). These records indicate reorganization of basal stresses both during and after the strong basal motion of event 2, during which part of the driving stress was transferred from the connected region to the hydraulically unconnected region near G2 and G3 (Fig. 10c). This transfer of basal stress results in enhanced basal shear and/or glacier sliding in the unconnected region, and elevated geophone counts in the records for G2 and G3 (Fig. 8 b and c).

Event 3 occurs at $1820 \mathrm{~h}, 40 \mathrm{~min}$ prior to peak diurnal pressure on day 162. Transient responses are noted in the records for six pressure transducers at this time (Fig. 2c); no step changes are recorded during the event. While the failure of six pressure transducers during event 2 precludes measurement in those locations, the relatively minor responses indicated by surviving pressure transducers suggest that pulse magnitudes during event 3 are lower than those during events 1 and 2. Responses noted in the records for conductivity and turbidity sensors are similar to those recorded during events 1 and 2. Glacier motion during event 3 is indicated by strong responses in records for two ploughmeters. Failure of PLl (Fig. 6a) occurs at this time, and the record for PL2 (Fig. 6c) shows a transient force increase during the event.

No evidence for strong basal motion is seen in the instrument records for several weeks following event 3, suggesting that the mechanical adjustments made during the course of the events resulted in a stable configuration of basal stresses. Relocation of the sticky spot to the unconnected region during the events (Fig. 10d) likely contributed greatly to glacier stability, as sediments there 
are less susceptible to pressure-induced weakening than are sediments in the connected region.

\section{GONCLUSIONS}

While the events of 11 June 1995 clearly demonstrate that changes in subglacial hydrological conditions strongly influence glacier dynamics, they also serve to illustrate how unstable situations can be quickly accommodated by mechanical adjustments at the glacier bed. Pressuretransducer records indicate that hydraulic connection was established simultaneously over a $\sim 20000 \mathrm{~m}^{2}$ area, creating a region of instability that could have covered much of this region. This raises the question of how the glacier response would have differed had the unstable region been larger. Any part of the driving stress not supported by the unstable region would be transferred to surrounding regions (e.g. Truffer and others, 2000). Sufficiently large transferred stresses could exceed the strength of sediments in the regions balancing the driving stress or of the ice itself. Extensive failure at the ice-bed interface could result in widespread mechanical instability and, ultimately, glacier surging. Because the removal of basal waters increases coupling between the glacier and its bed, it is likely that the establishment of a high-capacity drainage system precludes formation of an unstable region large enough to enable surging.

\section{AGKNOWLEDGEMENTS}

This research was funded by the Natural Sciences and Engineering Research Council of Canada. We thank Parks Canada for permitting the fieldwork to be conducted in Kluane National Park. C. Davis, U. H. Fischer, G. E. Flowers, K.-N. Foo, D. H. D. Hildes, E. Walker and many others helped with data collection on Trapridge Glacier; D. Schreiber assisted in the fabrication of the instruments. We thank U. Fischer and I. Willis for constructive and insightful reviews, and the Scientific Editor, J. Glen.

\section{REFERENCES}

Alley, R. B. 1993. In search of ice-stream sticky spots. F. Glaciol., 39(133), 447-454.

Alley, R. B. 1996. Towards a hydrologic model for computerized ice-sheet simulations. Hydrol. Processes, 10, 649-660.

Blake, E., G. K. C. Clarke and M. G. Gérin. 1992. Tools for examining subglacial bed deformation. F. Glaciol., 38(130), 388-396.

Blake, E.W., U. H. Fischer and G. K. G. Clarke. 1994. Direct measurement of sliding at the glacier bed. F. Glaciol., 40(136), 595-599.

Boulton, G.S. and R. C.A. Hindmarsh. 1987. Sediment deformation beneath glaciers: rheology and geological consequences. 7. Geophys. Res., 92(B9), 9059-9082.

Boulton, G. S., D. L. Dent and E. M. Morris. 1974. Subglacial shearing and crushing, and the role of water pressures in tills from south-east Iceland. Geogr. Ann., 56A (3-4), 135-145.

Clarke, G. K. C. 1987. Subglacial till: a physical framework for its properties and processes. 7. Geophys. Res., 92(B9), 9023-9036.

Fischer, U. H. and G. K. C. Clarke. 1994. Ploughing of subglacial sediment. 7. Glaciol., 40 (134), 97-106.

Fischer, U. H. and G. K. C. Clarke. 1997. Stick-slip sliding behaviour at the base of a glacier. Ann. Glaciol., 24, 390-396.

Fischer, U. H. and G. K. C. Clarke. In press. A review of subglacial hydro- mechanical coupling: Trapridge Glacier, Canada. Ouat. Int.

Fischer, U. H., N. R. Iverson, B. Hanson, R. LeB. Hooke and P. Jansson. 1998. Estimation of hydraulic properties of subglacial till from ploughmeter measurements. F. Glaciol., 44(148), 517-522.

Gordon, S., M. Sharp, B. Hubbard, C. Smart, B. Ketterling and I. Willis. 1998. Seasonal reorganization of subglacial drainage inferred from measurements in boreholes. Hydrol. Processes, 12, 105-133.

Harbor, J., M. Sharp, L. Copland, B. Hubbard, P. Nienow and D. Mair. 1997. The influence of subglacial drainage conditions on the velocity distribution within a glacier cross section. Geology, 25(8), 739-742.

Harrison, W. D., K. A. Echelmeyer and H. Engelhardt. 1993. Short-period observations of speed, strain and seismicity on Ice Stream B, Antarctica. 7. Glaciol., 39 (133), 463-470.

Hock, R. 1993. Comparison of ventilated and unventilated air temperature measurements. In Tarfala Research Station annual report 1992-93. Stockholm, Stockholms Universitet. Naturgeografiska Institutionen, 16-19. (Forskningsrapport 100.)

Hooke, R. LeB., B. Hanson, N. R. Iverson, P. Jansson and U. H. Fischer. 1997. Rheology of till beneath Storglaciären, Sweden. f. Glaciol., 43(143), 172-179.

Hubbard, B. P., M. J. Sharp, I. C. Willis, M. K. Nielsen and C. C. Smart. 1995. Borehole water-level variations and the structure of the subglacial hydrological system of Haut Glacier d'Arolla, Valais, Switzerland. F. Glaciol., 41 (139), 572-583.

Iken, A. and R.A. Bindschadler. 1986. Combined measurements of subglacial water pressure and surface velocity of Findelengletscher, Switzerland: conclusions about drainage system and sliding mechanism. f. Glaciol., 32(110), 101-119.

Iken, A., H. Röthlisberger, A. Flotron and W. Haeberli. 1983. The uplift of Unteraargletscher at the beginning of the melt season - a consequence of water storage at the bed? F. Glaciol., 29(101), 28-47.

Iverson, N. R. 1999. Coupling between a glacier and a soft bed. II. Model results. F. Glaciol., 45 (149), 41-53.

Iverson, N. R., P. Jansson and R. LeB. Hooke. 1994. In-situ measurement of the strength of deforming subglacial till. f. Glaciol., 40(136), 497-503.

Iverson, N. R., R.W. Baker and T. S. Hooyer. 1997. A ring-shear device for the study of till deformation: tests on tills with contrasting clay contents. Quat. Sci. Rev., 16(9), 1057-1066.

Iverson, N. R., T. S. Hooyer and R. W. Baker. 1998. Ring-shear studies of till deformation: Coulomb-plastic behavior and distributed strain in glacier beds. F. Glaciol., 44(148), 634-642.

Iverson, N. R., R.W. Baker, R. LeB. Hooke, B. Hanson and P. Jansson. 1999. Coupling between a glacier and a soft bed. I. A relation between effective pressure and local shear stress determined from till elasticity. F. Glaciol., 45 (149), 31-40.

Jansson, P. 1995. Water pressure and basal sliding on Storglaciären, northern Sweden. F. Glaciol., 41 (138), 232-240.

Kamb, B. and H. Engelhardt. 1987. Waves of accelerated motion in a glacier approaching surge: the mini-surges of Variegated Glacier, Alaska, U.S.A. 7. Glaciol., 33(113), 27-46.

Kavanaugh, J. L. 2000. Hydromechanical behaviour of a surge-type glacier: Trapridge Glacier, Yukon Territory, Canada. (Ph.D. thesis, University of British Columbia.)

Kavanaugh, J. L. and G. K. C. Clarke. 2000. Evidence for extreme pressure pulses in the subglacial water system. F. Glaciol., 46(153), 206-212.

Murray, T. and G. K. C. Clarke. 1995. Black-box modeling of the subglacial water system. 7. Geophys. Res., 100 (B7), 10,231-10,245.

Röthlisberger, H. and H. Lang. 1987. Glacial hydrology. In Gurnell, A.M. and M.J. Clark, eds. Glacio-fluvial sediment transfer: an alpine perspective. Chichester, etc., John Wiley and Sons, 207-284.

Stone, D. B. 1993. Characterization of the basal hydraulic system of a surgetype glacier: Trapridge Glacier, 1989-92. (Ph.D. thesis, University of British Columbia.)

Stone, D. B. and G. K. C. Clarke. 1996. In situ measurements of basal water quality and pressure as an indicator of the character of subglacial drainage systems. Hydrol. Processes, 10 (4), 615-628.

Stone, D. B., G. K. C. Clarke and E.W. Blake. 1993. Subglacial measurement of turbidity and electrical conductivity. F. Glaciol., 39(132), 415-420.

Truffer, M., W. D. Harrison and K. A. Echelmeyer. 2000. Glacier motion dominated by processes deep in underlying till. f. Glaciol., 46(153), 213-221.

Tulaczyk, S. M., B. Kamb and H. F. Engelhardt. 2000. Basal mechanics of Ice Stream B, West Antarctica. I. Till mechanics. f. Geophys. Res., 105(B1), 463-481. 